\title{
Right heart echo case selection — possible pitfalls
}

Nikša Drinković Jr*, Nikša Drinković, Jadranka Šeparović Hanževački, Sanja Ceković, Vlatka Rešković Lukšić, Kristina Marić Bešić

University Hospital Center Zagreb, Zagreb, Croatia

\section{Subvalvular pulmonic stenosis}

Possible overestimation of subvalvular pulmonic stenosis severity can occur in presence of small membranous VSD when high velocity VSD flow is merging low velocity subvalvular stenotic flow (Figure 1). In our 33-year-old patient, however, inside a $5.2 \mathrm{~m} / \mathrm{s}$ VSD jet a lower velocity $2.4 \mathrm{~m} / \mathrm{s} \mathrm{jet}$ originated from pulmonic stenosis was appreciated and peak Doppler gradient of $23 \mathrm{mmHg}$ measured (Figure 2). Cardiac vascular magnetic resonance (MR) confirmed presence of subvalvular pulmonic stenosis with maximal velocity between 2.3 and $2.7 \mathrm{~m} / \mathrm{s}$, and on cardiac catheterization gradient of less than $30 \mathrm{mmHg}$ was registered.
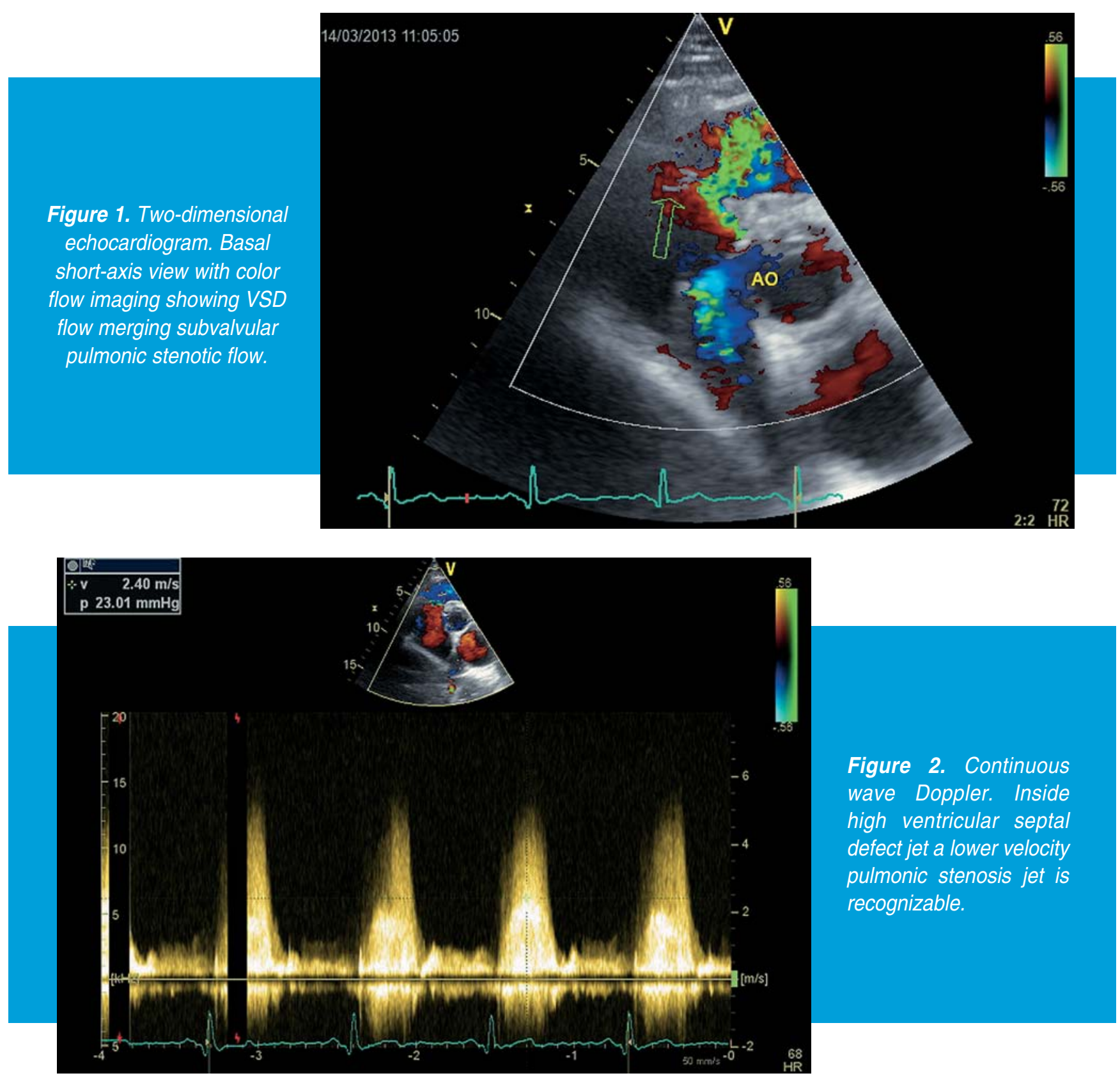


\section{Chronic constrictive pericarditis}

In a 69-year-old patient with minimal effort dyspnea, aneurysmatic dilatation of prominently trabeculated RV apex was observed on TTE which at the first glance raised suspicion on arrhythmogenic right ventricular dysplasia/cardiomyopathy (Figure 3). However, apical contractility was preserved and subcostal view revealed increased pericardial thickness (up to $1.2 \mathrm{~cm}$ ) in the region of free RV wall indicating pericardial constriction to be responsible for aneurysmatic RV remodeling. Furthermore, all echo and Doppler parameters of pericardial constriction were present and pathologically thickened pericardium (up to $2 \mathrm{~cm}$ ) was seen on MR and 0.5 $\mathrm{cm}$ bright calcifications on CT scan.

\section{Mechanical tricuspid valve thrombosis}

Three-dimensional transthoracic echocardiography (3D TTE) allows visualization of all three leaflets of tricuspid valve (TV) and accurate assessment of TV orifice area in TV stenosis. A 32-year-old patient with mechanical tricuspid valve replacement performed 10 years ago was admitted with progressive dyspnea and right heart failure. TTE re- vealed artificial valve thrombosis and severe stenosis dense immobile leaflets, TTF-E $213 \mathrm{~m} / \mathrm{s}$, mean pressure gradient $15 \mathrm{mmHg}$, pressure half time $230 \mathrm{~ms}$. 3D TTE from right atrial aspect revealed immobile leaflets, large floating thrombus. In attempt to find effective orifice area we first measured false orifice area created by mobile thrombus which in fact appeared in systole. In addition we found a true diastolic orifice and area of $0.4 \mathrm{~cm}^{2}$. 3D TTE examination completed echocardiographic study and there was no need for transesophageal echocardiography. The patient underwent tricuspid valve replacement and bioprosthetic valve was implanted with a good result.

KEYWORDS: echocardiography, pulmonic stenosis, constrictive pericarditis, tricuspid valve thrombosis.

\section{Received: $20^{\text {th }}$ Mar 2013}

*Address for correspondence: Klinički bolnički centar Zagreb, Kišpatićeva 12, HR-10000 Zagreb, Croatia.

Phone: +385-1-2388-888

E-mail: pimg@zg.t-com.hr

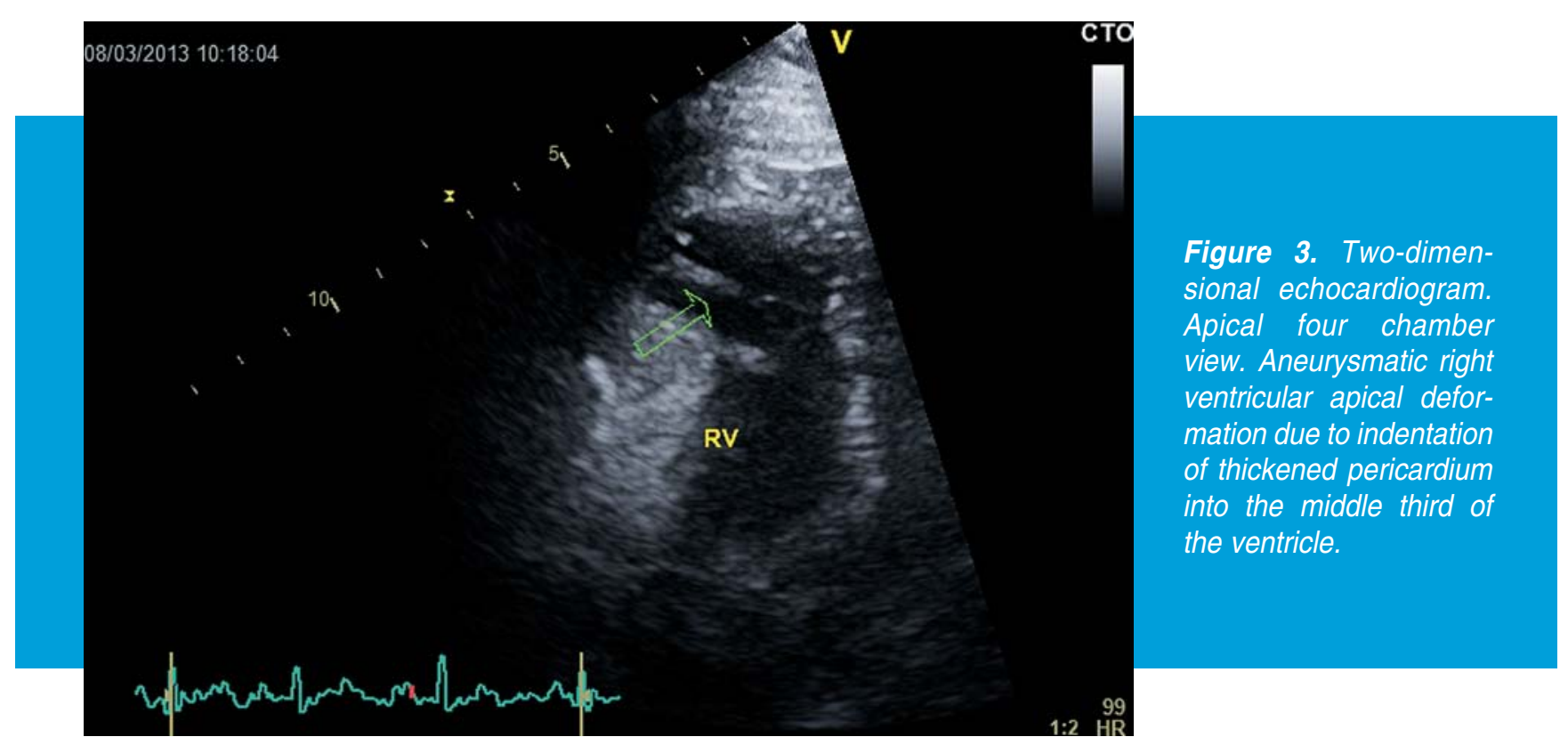

\section{Literature}

1. Prakasa KR, Dalal D, Wang J, Bomma C, et al. Feasibility and variability of three dimensional echocardiography in arrhythmogenic right ventricular dysplasia/cardiomyopathy. Am J Cardiol. 2006;97:703-9.

2. Pothineni KR, Duncan K, Yelamanchili P, Nanda NC. Live/real time three-dimensional transthoracic echocardiographic assessment of tricuspid valve pathology: incremental value over two-dimensional technique. Echocardiography. 2007;24:541-52. 